\title{
$O$ ato de coletar espécimes silvestres e a legislação brasileira ${ }^{1}$
}

\section{The act of collecting wild specimens and Brazilian law}

\author{
Aline Maisa Lubenow ${ }^{2}$ \\ Magali Romero Sá ${ }^{3}$
}

\begin{abstract}
Resumo: O presente artigo tem por objetivo analisar as atividades de coleta científica desenvolvidas pelo coletor e colecionador alemão Fritz Plaumann e o impacto causado ao trabalho de Plaumann a partir das modificações na legislação ambiental brasileira na década de 1960. Destaque será dado a promulgação da lei $\mathrm{N}^{\circ} 5.197$ de 1967 , conhecida como Lei de proteção à fauna, e como essa nova lei afetou o ato de coletar e comercializar espécimes silvestres.
\end{abstract}

Palavras-chave: Coleção científica, Legislação ambiental brasileira, comercialização de espécimes, Fritz Plaumann;

\begin{abstract}
This article aims to analize the activities of collecting scientific material by the German collector and collector Fritz Plaumann, and the impact caused in these activities by the alterations in Brazilian environmental legislation in the 1960's. Particular emphasis will be given to the adoption of the Law $\mathrm{N}^{\circ}$ 5.197/ 1967, known as Fauna Protection Act, and how this affected the work of scientists and amateur collectors regarding the collection and commercialization of wild specimens.
\end{abstract}

Keywords: Scientific collection, Brazilian environmental legislation, specimens commercialization, Fritz Plaumann.

\footnotetext{
${ }^{1}$ Este artigo é parte do terceiro capítulo da dissertação de mestrado de Aline Maisa Lubenow intitulada: "Enveredando pelas matas do sertão catarinense: a coleção entomológica Fritz Plaumann" sob orientação da professora Dra Magali Romero Sá.

${ }^{2}$ Mestre em História das Ciências e da Saúde pela Casa de Oswaldo Cruz/Fundação Oswaldo Cruz. E-mail: alinemaisaa21@gmail.com

${ }^{3}$ Doutora em History and Philosophy of Science pela University of Durham. É pesquisadora da Casa de Oswaldo Cruz/Fundação Oswaldo Cruz e professora do Programa de PósGraduação em História das Ciências e da Saúde (COC/Fiocruz), sendo atualmente vicediretora de Pesquisa, Educação e Divulgação Científica da Casa de Oswaldo Cruz. E-mail: $\underline{\text { magali@fiocruz.br }}$
} 


\section{Introdução}

Coletar e comercializar espécimes da fauna brasileira era uma atividade desenvolvida no Brasil desde a abertura dos portos por D. João VI em 1808. Naturalistas estrangeiros aportavam na ex-colônia portuguesa e escrutinavam o território brasileiro em busca de espécimes para serem incorporados às coleções dos museus europeus e norte-americanos e também às coleções particulares. A atividade de coleta não estava restrita somente aos especialistas, mas era também realizada por comerciantes de material de história natural. Essa atividade era altamente lucrativa e tinha uma demanda crescente no mercado, tanto pelas instituições científicas, que pagavam a esses coletores para fornecerem material para suas coleções, quanto aos particulares que mantinham coleções específicas de grande valor no mercado.

Esse foi o caso do imigrante alemão Fritz Plaumann, que chegou ao Brasil em 1924 com seus pais, e se instalou na colônia alemã de Nova Teutônia (atualmente Seara, SC), na região oeste de Santa Catarina. A vinda para o Brasil da família Plaumann foi motivada pela grande crise econômica na qual se encontrava a Alemanha depois da Primeira Guerra Mundial.

Já nos anos de 1930 Fritz Plaumann dá início às atividades de coletor e colecionador de insetos na região do Alto Uruguai Catarinense, formando uma grande coleção de insetos e estabelecendo contato com diversas instituições científicas, pesquisadores e colecionadores de vários países, incluindo o Brasil. Por se encontrar em uma região pouco explorada cientificamente, Plaumann passou a receber demandas de várias instituições estrangeiras e sua atividade de coletor ganhou destaque internacional logo em meados da mesma década.

Através da atividade de coleta e colecionismo de insetos Plaumann construiu uma rede científica que possibilitou a circulação de conhecimento e a comercialização de espécimes, e, pelo meio de permutas, adquiriu muitos equipamentos e literatura específica para seus estudos. Como enfatizado por Fan, ${ }^{4}$ é por meio dessas redes que são transmitidas informações fundamentais para a troca e encontros globais, e foi assim, movimentando ideias e conhecimento a respeito de práticas de coleta e taxonomia dos artrópodes que Plaumann construiu uma carreira como entomologista amador.

A coleta científica realizada por Plaumann contribuiu para a ampliação da representação de insetos da região sul do Brasil nas coleções de

\footnotetext{
${ }^{4}$ FAN, Fa-ti.The Global Turn in the History of Science. In. East Asian Science, Technology and Society: An International Journal, p. 252, 2012.
} 
diversos museus, como o Natural History Museum de Londres, o Museum für Naturkunde de Berlim, o American Museum of Natural History de Nova York, o Museu Nacional do Rio de Janeiro, o Museu da Universidade Federal do Paraná, o Museu de Zoologia da Universidade de São Paulo, dentre outros. Além das instituições científicas, Plaumann também contribuiu para o aumento de várias coleções particulares, como por exemplo, a do colecionador brasileiro Carlos Alberto Seabra.

A própria coleção entomológica de Plaumann se tornou uma referência abrigando uma grande representatividade de espécies da fauna da Mata Atlântida do sul do Brasil. São quase 80 mil exemplares, 17 mil espécies, sendo que aproximadamente mil foram descobertas por ele e graças aos seus interlocutores nacionais e estrangeiros, foram descritas e publicadas. Muitas das espécies descobertas por Plaumann levaram seu nome, uma forma dos especialistas prestarem homenagem a ele. ${ }^{5}$

Este artigo tem por objetivo analisar as atividades de coleta científica realizadas pelo coletor e colecionador Fritz Plaumann e o impacto causado ao trabalho desse naturalista amador com as mudanças na legislação ambiental brasileira a partir da década de 1960.

\section{A legislação brasileira e o impacto nas atividades de coleta científica}

Até fins de 1960 nenhuma legislação interferiu nas atividades de coleta e na comercialização de espécimes da fauna brasileira. As primeiras medidas de proteção à nossa fauna e flora foram adotadas na segunda metade do século XIX e, em sua maioria, relacionadas às atividades extrativistas e de caça e pesca. Essas medidas foram adotadas pelos governos provinciais em forma de leis municipais, visando a regulamentação do comércio regional ${ }^{6}$.

\footnotetext{
${ }^{5}$ Para mais detalhes sobre a vinda de Plaumann para o Brasil e suas atividades como coletor e colecionador ver em: LUBENOW, Aline Maisa. Enveredando pelas matas do sertão catarinense: a coleção entomológica Fritz Plaumann. (Dissertação de mestrado) Casa de Oswaldo Cruz/Fiocruz. Rio de Janeiro, 2015.

6 COSTA, Kelerson Semerene. Intervenções humanas na natureza amazônica. Ciência e Ambiente, n. 33, p. 81-96, 2006.
} 
Na legislação brasileirado século XX encontramos referências a respeito da fauna brasileira no código civil de 1916, artigo 593, referindo-se aos animais domésticos e silvestres como:

Art. 593. São coisas sem dono e sujeitas à apropriação:

I - os animais bravios, enquanto entregues à sua natural liberdade;

II - os mansos e domesticados que não forem assinalados, se tiverem perdido o hábito de voltar ao lugar onde costumam recolher-se, salvo a hipótese do art. 596;

III - os enxames de abelhas, anteriormente apropriados, se o dono da colmeia, a que pertenciam, os não reclamar imediatamente;

IV - as pedras, conchas e outras substâncias minerais, vegetais ou animais arrojadas às praias pelo mar, se não apresentarem sinal de domínio anterior. ${ }^{7}$

O Código Civil possuía ainda artigos específicos sobre a caça e a pesca de animais discriminando que só era permitido caçar e pescar em terras e águas particulares com consentimento do proprietário. A posse de espécies era delimitada a partir da sua apropriação por um particular. Se um determinado animal fosse caçado passaria a ser de posse do caçador e eram considerados como bens móveis, como explicito no artigo 595: "Pertence ao caçador o animal por ele apreendido. Se o caçador for no encalço do animal e o tiver ferido, este lhe pertencerá, embora outrem o tenha apreendido". ${ }^{8}$

Muitas dessas disposições do código de 1916 foram revogadas na lei de proteção à fauna de 1967 que declarou-que todos os animais da fauna silvestre do Brasil pertencem à união e não mais a propriedades privadas ${ }^{9}$.

\footnotetext{
${ }^{7}$ Disponível em: http://www.jusbrasil.com.br/topicos/11442811/artigo-593-da-lei-n-3071-de01-de-janeiro-de-1916.

${ }^{8}$ Disponível em: http://www.jusbrasil.com.br/topicos/11442572/artigo-595-da-lei-n-3071-de01-de-janeiro-de-1916. Acessado em: 04/02/2016.

${ }^{9}$ MARTINS, Thiago de Souza. A convenção sobre o comércio internacional das espécies da fauna e da flora selvagens em perigo de extinção (CITES) e sua implantação no Brasil: das expectativas de proteção à mercantilização da vida. (Dissertação de mestrado) Universidade Federal de Santa Catarina, Florianópolis, p.138, 2007.
} 
Medidas de proteção aos animais aparecem em 1934 quando o então presidente da república Getúlio Vargas promulga o decreto $\mathrm{N}^{\circ} 24.645$, que estabelece pena de multa a quem maltratasse os animais. $\mathrm{O}$ artigo $3^{\circ}$ é específico sobre esse assunto, e arrola 31 maneiras que considera como maus tratos, entre elas:

I - praticar ato de abuso ou crueldade em qualquer animal;

XXIII - ter animais destinados à venda em locais que não reúnam as condições de higiene e comodidades relativas;

XXVIII - exercitar tiro ao alvo sobre patos ou qualquer animal selvagem exceto sobre os pombos, nas sociedades, clubes de caça, inscritos no Serviço de Caça e Pesca;

XXXI - transportar, negociar ou cair, em qualquer época do ano, aves insetívoras, pássaros canoros, beija-flores e outras aves de pequeno porte, exceção feita das autorizações para fins científicos, consignadas em lei anterior; $^{10}$

Até fins de 1960 nenhuma legislação havia interferido nas atividades de coleta e na comercialização de espécimes realizado por Plaumann. No entanto, a lei $\mathrm{n}^{\circ}$ 5.197, de 03 de janeiro de 1967, conhecida como Lei de proteção à fauna, restringiu o ato de coletar e fez com que algumas barreiras cruzassem o caminho do coletor, impossibilitando suas remessas de materiais científicos ao exterior, incluindo a realização da coleta para sua própria coleção.

As condições de coleta impostas pela lei de Proteção à Fauna impunha a necessidade de regulação de transporte de espécimes silvestres e a coleta para fins científicos. Em seus artigos assim estava discriminado:

Art. $1^{\circ}$ Os animais de quaisquer espécies, em qualquer fase do seu desenvolvimento e que vivem naturalmente

10 O decreto foi revogado pelo Decreto $\mathrm{n}^{\mathbf{0}}$ 11, de 1991. Disponível em: http://www.planalto.gov.br/ccivil_03/decreto/1930-1949/D24645.htm. 
fora do cativeiro, constituindo a fauna silvestre, bem como seus ninhos, abrigos e criadouros naturais são propriedades do Estado, sendo proibida a sua utilização, perseguição, destruição, caça ou apanha.

Art. $6^{\circ} \mathrm{O}$ Poder Público estimulará:

a) a formação e o funcionamento de clubes e sociedade amadoristas de caça e de tiro ao vôo, objetivando alcançar o espírito associativista para a prática desse esporte.

b) a construção de criadouros destinados à criação de animais silvestres para fins econômicos e industriais.

Art. 13 para exercício da caça, é obrigatória a licença anual, de caráter específico e de âmbito regional, expedida pela autoridade competente;

Art. 14 que poderá ser concedida a cientistas, pertencentes a instituições científicas, oficiais ou oficializadas, ou por estas indicadas, licença especial para a coleta de material destinado a fins científicos, em qualquer época.

Art. 16. Fica instituído o registro das pessoas físicas ou jurídicas que negociem com animais silvestres e seus produtos.

Art. 19. O transporte interestadual e para o Exterior, de animais silvestres, lepidópteros, e outros insetos e seus produtos, depende de guia de trânsito, fornecida pela autoridade competente.

Parágrafo único. Fica isento dessa exigência o material consignado a Instituições Científicas Oficiais. ${ }^{11}$

Para Plaumann, por ser um autodidata e sem nenhum vínculo com nenhuma instituição científica, a obtenção das licenças se tornava mais trabalhosa.

Os acontecimentos que ocorreram no cenário internacional na década de 1970 tiveram influência direta na legislação ambiental brasileira. A começar com a Convenção sobre Comércio Internacional das Espécies da Flora e Fauna Selvagens em Perigo de Extinção (CITES) ocorrida em

\footnotetext{
${ }^{11}$ Disponível em: www.rbma.org.br/anuario/pdf/legislacao_13.pdf. Acessado em: 13 de abril de 2015 .
} 
Washington, em 3 de março de 1973, aprovada no Brasil pelo Decreto Legislativo $\mathrm{n}^{\circ} 54$ de 1975 e promulgada pelo Decreto no 76.623, de 24 de junho 1975. A convenção contou com a participação de 175 países consignatários, tendo como objetivo principal o de estabelecer um modelo jurídico internacional para regular o comércio de espécies da fauna e flora, prevenindo-as do perigo de extinção pelo comércio internacional. $\mathrm{O}$ acordo firmado na convenção foi considerado um dos mais importantes para a preservação de espécies ${ }^{12}$ e estabeleceu uma lista de espécies que só poderiam ser importados e exportados mediante autorizações. A convenção continha três anexos, dependendo do grau de risco de extinção das espécies. No anexo 1 estavam as espécies que mais poderiam ser afetadas pelo comércio. No anexo 2, as espécies que não estavam em perigo de extinção, mas poderão chegar a estar e, no anexo 3 , as espécies que necessitavam de algum tipo de regulamentação para exportação.

No caso específico da CITES, os Estados que assinaram e ratificaram a convenção devem implementar as obrigações existentes no texto do Tratado em fases distintas, que vão desde a adoção de medidas legislativas e econômicas relativas ao comércio de animais silvestres até o desenvolvimento de um sistema de informações correspondentes ao conteúdo do Tratado, que deve estar à disposição dos cidadãos para eventuais consultas. Além disso, cada uma das Partes deve transmitir periodicamente à Secretaria CITES informações referentes ao volume do comércio e às medidas tomadas para tornar efetivas as obrigações internacionais, como é o caso dos mecanismos de enforcement, por exemplo. ${ }^{13}$

\footnotetext{
12 Segundo o texto original promulgada na respectiva data. Recognizing that wild fauna and flora in their many beautiful and varied forms are an irreplaceable part of the natural systems of the earth which must be protected for this and the generations to come; Conscious of the ever-growing value of wild fauna and flora from aesthetic, scientific, cultural, recreational and economic points of view; Recognizing that peoples and States are and should be the best protectors of their own wild fauna and flora; Recognizing, in addition, that international cooperation is essential for the protection of certain species of wild fauna and flora against overexploitation through international trade; Convinced of the urgency of taking appropriate measures to this end. Disponível em:
} http://www.mma.gov.br/estruturas/sbf_chm_rbbio/_arquivos/cites_ibama_72.pdf. Acessado em: 14 de abril de 2015.

${ }^{13}$ MARTINS, Thiago de Souza. A convenção sobre o comércio internacional das espécies da fauna e da flora selvagens em perigo de extinção (CITES) e sua implantação no Brasil: das 
Fritz Plaumann foi diretamente afetado pelas discussões e resoluções tomadas na CITES. O coletor lamentou o bloqueio de suas remessas ao exterior, enfatizando que eram indispensáveis para dar continuidade ao levantamento da fauna regional. Como narrou no trecho a seguir, o fato ocorreu posteriormente à aprovação do decreto no Brasil. Só poderiam ser enviadas remessas para o exterior acompanhadas de um Guia de Trânsito do IBDF.

No final do ano de 1975, foram-me devolvidas pelo correio duas caixinhas com material entomológico, destinadas a instituições científicas da Alemanha. Não sabia o que fazer. Dava-se que nesses dias recebi a visita do pessoal do Ministério da Agricultura, que me informava que esse assunto deveria ser tratado com o Instituto Brasileiro de Desenvolvimento Florestal-IBDF. Depois de esclarecido o assunto em questão, recebi do delegado em exercício a autorização para coletar material entomológico para fins científicos, não podendo a licença ser usada para fins comerciais e esportivos, estando isento de acompanhamento a guia de trânsito quando o material fosse consignado a instituições cientificas oficiais. ${ }^{14}$

Além da CITES, na década de 1970, ocorreu a Conferência das Nações Unidas sobre o Meio Ambiente Humano, reunida em Estocolmo de 5 a 16 de junho de 1972. O cenário internacional abriu suas portas para as discussões que permeavam a preservação da fauna e flora, que, no período, encontravam-se latentes através de debates voltados à preservação e conservação do meio ambiente para a humanidade. A declaração envolvia aspectos essenciais para o bem-estar do homem. Pontuava que era um dever de todos os governos e povos a proteção e o melhoramento do meio ambiente e que salvaguardar o meio ambiente era o melhor caminho a ser seguido a partir da adoção, normas e medidas apropriadas para enfrentar os problemas

expectativas de proteção à mercantilização da vida. (Dissertação de mestrado) Universidade Federal de Santa Catarina, Florianópolis, p.63. 2007.

14 SPESSATTO, Mary, Bortolanza. (org). O diário de Fritz Plaumann. Chapecó: Argos, 2001. p.164. 
que afligiam o contexto mundial no período, como a destruição de amplas áreas de florestas, a poluição e o esgotamento de recursos hídricos.

Um aspecto importante para esta pesquisa era a extinção expressiva da fauna e flora mundiais. Um ponto ressaltado na convenção foi o amplo auxílio que a ciência e a tecnologia poderiam proporcionar para a busca por solução desses problemas gravíssimos do meio ambiente.

Com o progresso social e os avanços da produção, da ciência e da tecnologia, a capacidade do homem de melhorar o meio ambiente aumenta a cada dia que passa [...] A Conferência encarece aos governos e aos povos que unam esforços para preservar e melhorar o meio ambiente humano em benefício do homem e de sua posteridade. $^{15}$

Foram estabelecidos na conferência 26 princípios, sendo dois deles enfatizados abaixo e que se referem à conservação e preservação da fauna e da flora.

Princípio 2: Os recursos naturais da terra incluídos o ar, a água, a terra, a flora e a fauna e especialmente amostras representativas dos ecossistemas naturais devem ser preservados em benefício das gerações presentes e futuras, mediante uma cuidadosa planificação ou ordenamento.

Princípios 4: O homem tem a responsabilidade especial de preservar e administrar judiciosamente o patrimônio da flora e da fauna silvestres e seu habitat, que se encontram atualmente, em grave perigo, devido a uma combinação de fatores adversos. Consequentemente, ao planificar o desenvolvimento econômico deve-se atribuir importância à conservação da natureza, incluídas a flora e a fauna silvestres. ${ }^{16}$

${ }^{15}$ Disponível em: www.mma.gov.br/estruturas/agenda21/_arquivos/estocolmo.doc. Acessado em: 20 de abril de 2015.

16 Disponível em: www.mma.gov.br/estruturas/agenda21/_arquivos/estocolmo.doc. Acessado em: 20 de abril de 2015. 
Nesse sentido, a Convenção sobre Comércio Internacional das Espécies da Flora e Fauna Selvagens em Perigo de Extinção (CITES), de 1973, e a Conferência das Nações Unidas sobre o Meio Ambiente Humano, de 1972, impulsionaram no cenário internacional uma regulamentação mais rígida quanto à exportação e coleta de espécimes, principalmente se tratando de espécies em extinção ou da fauna silvestre.

\section{A luta de Fritz Plaumann pela autorização para coleta e comercialização de espécimes}

Na década de 1970, Plaumann permaneceu em pleno contato com a direção do $\operatorname{IBDF}^{17}$ (Instituto Brasileiro de Desenvolvimento Florestal), visando solicitar autorização para a coleta de espécimes e comercialização. Contudo, suas remessas para o exterior foram proibidas no decorrer na década de 1970, o que fez com que as relações científicas que ele havia estabelecido com parceiros nacionais e internacionais ficassem seriamente abaladas, como expressou em carta para Pe. Jesus Moure:

Para colecionar mais material surgiu inesperadamente dificuldades com o IBDF e desde fim do mês de novembro do ano passado toda minha atividade entomológica teve que parar. Eu possuía uma AUTORIZAÇÃO para colecionar material entomológico para fins scientificos do delegado para S.O. em Joinville, mas deu-se que este foi aposentado e a Delegacia transferida para Florianópolis, e o encarregado do Delegado para tratar deste assunto Dr. Orly achava (quando mostrei a ele a dita autorização) que não mereço tal autorização: $1^{\circ}$ por não ter a habilidade para tal serviço; $2^{\circ}$ por não sendo ligado a uma instituição oficial. Talvez seria aconselhável que o amigo dirigisse uma carta ao delegado em Florianópolis convencendo-os que realmente possuo os conhecimentos e práticas exigidas pela lei 5.197 Art. 14 e solicitando que posso continuar para colecionar

\footnotetext{
${ }^{17} \mathrm{O}$ Instituto Brasileiro de desenvolvimento florestal (IBDF) foi criado pelo Decreto-Lei $\mathrm{N}^{\circ}$ 289, de 28 de fevereiro de 1967. Foi vinculado ao Ministério da Agricultura, com a finalidade de construir uma política florestal no país, bem como promover a proteção e a conservação dos recursos naturais. Disponível em: http://www.planalto.gov.br/ccivil_03/decreto-lei/19651988/Del0289.htm. Acessado em: 13 de abril de 2015.
} 
material scientífico para a Universidade. Tenho a impressão que talvez o IBDF de Florianópolis age sob a influencia de alguns dos atacadistas de material entomológico primeiramente para fins industriais os quais pretendem paralisar toda a atividade de outros entomólogos que não trabalham com eles. [...] Por isso fui a Florianópolis para esclarecer o assunto, porém o dito encarregado Dr. Orly Joaquim de Carvalho me deu três meses de prazo para legalizar a minha atividade sob a ameaça -se não cumprir- de então dar uma batida com a polícia federal e confiscar todo o material entomológico encontrado inclusive minha coleção!! Disse que tinha dois tipos para a incisão, um para criadores e outros para negociantes, visto que nunca me considerava comerciante então foi combinado de pedir registro como CRIADOURO DE INSETOS PARA FINS SCIENTIFICOS, visto que logo vou fazer 76 anos foi combinado que o registro podia ser feito em nome da minha filha adotiva. Fiz dito requerimento, porém, visto que tudo esta muito demorado até hoje não recebi o ALVARA para esse fim. Mas somente isso nunca resolverá o caso em questão, visto que a finalidade da minha atividade entomológica não estava e nunca será unicamente "um negocio", porém é de estudar e conhecer a fauna regional desta zona a qual está desaparecendo rapidamente motivo do excesso do uso de venenos na agricultura, e de achar espécies novas para que podem ser descritos para aproveito por futuras gerações, o DDT vai acabar com tudo, infelizmente perante a lei o único culpado para isto parece que vai ficar para sempre o entomólogo que pega uns para fins scientíficos, sempre estava contra a matança de borboletas para fins industriais, porém, me parece que os atacadistas não tem dificuldade de exportar dito material, lendo os anúncios nos periódicos de outros países. Pelo meu ver essa lei 5.197 devia ser modificada em conformidade com os conhecimentos scientíficos atuais, e em vez de dificultar os estudos dos insetos, enquanto ainda está em tempo, estimula-se. ${ }^{18}$

\footnotetext{
${ }^{18}$ Trecho extraído de correspondência de Fritz Plaumann a Pe. Jesus Moure. 5 de abril de 1978. Fonte: Casa de Fritz Plaumann.
} 
Não sabemos se Pe. Moure conseguiu ajudar Plaumann nessa situação. $\mathrm{O}$ que verificamos foi que o coletor solicitou auxílio para esse problema a outros professores da Universidade Federal do Paraná, mas não obteve resposta.

A restrição que afetou diretamente a Plaumann, referida no Art. 14 da Lei 5.197 de 1967, foi a de que somente cientistas que estivessem vinculados a alguma instituição científica e possuidores de licença especial poderiam realizar coletas de material científico. As restrições à coleta preocupavam Plaumann, principalmente devido à utilização de agrotóxico de forma descontrolada na agricultura da região oeste de Santa Catarina, o que estaria levando à extinção de algumas espécies ainda desconhecidas para a ciência.

Além disso, devemos ressaltar que, apesar de Plaumann se considerar um entomólogo amador, ele sabia de sua competência para coletar e identificar insetos, se julgando um profissional da área, apesar de, perante a legislação brasileira, ele ser considerado um mero amador que, sem vínculos institucionais, não poderia coletar. ${ }^{19}$

Para Drouin e Vicent, em fins do século XIX, os chamados "amadores" ou então "voluntários" eram destinados para o trabalho de campo. Havia, portanto, uma diferença entre "amadores" e as práticas "profissionais" exercidas nos laboratórios. O termo "amador" enfatizava uma falta de seriedade e confiabilidade. Porém, o "amador" deixou de ser somente um coletor e passou a formar sua própria coleção e a classificar o material que coletava, mas faltava a ele a credibilidade junto à comunidade científica adquirida por aqueles profissionais inseridos em instituições científicas. ${ }^{20}$

Plaumann era considerado um coletor e entomologista amador, sem formação profissional específica e sem estar ligado a nenhuma instituição científica, o que não o creditava junto às autoridades brasileiras como especialista em entomologia. ${ }^{21}$

\footnotetext{
${ }_{19}$ No século XVIII e primeira metade do século XIX, um cientista amado era aquele que podia contribuir para o avanço da ciência, liberto de constrangimentos materiais e/ou utilitários. A profissionalização da ciência acabou por redefinir os papéis e a influência dos amadores e a redução do papel que eles desempenhavam para o avanço científico.
}

20 DROUIN, Jean-Marc; Bernadette VINCENT-BENSAUDE. Nature for the people. JARDINE N.; SECORD, J.A. e SPARY, E.C. (eds).Cultures of natural history. Cambridge: Cambridge University Press, p- 417-419, 1997 (1996).

21 DROUIN, Jean-Marc; Bernadette VINCENT-BENSAUDE. Nature for the people.JARDINE, N.; SECORD, J.A. e SPARY, E.C. (eds).Cultures of natural history. 
Para Plaumann, os problemas que ele passou a enfrentar para coletar e continuar a manter o intercâmbio com instituições e pesquisadores brasileiros e estrangeiros aumentou a partir da promulgação do Art. 16 da lei 5.197, que exigia o registro específico para as pessoas que negociassem com animais silvestres.

No ano de 1977, ao tentar renovar a licença que tinha para coletar, Plaumann recebeu a notícia de que o IBDF havia bloqueado todas as remessas de insetos para o exterior. Antes disso, somente eram exigidas as guias de embarques ou licença para exportação, o que Plaumann possuía por ter se registrado como criador de insetos: "Afinal consenti em registrar-me como proprietário de um criadouro artificial de besouros, visto que a nossa região não estava apropriada para a criação de borboletas vistosas por causa do frio do inverno". ${ }^{22}$ Esta, então, foi a solução encontrada por Plaumann, junto ao IBDF para dar continuidade às suas atividades, mesmo que de modo reduzido.

Inicialmente, formou uma firma jurídica, seguindo as orientações do IBDF, em parceria com sua filha adotiva Gisela Margarida Germendorff Plaumann. Segundo o contrato social estabelecido, a denominação social ficava como "Entomologia Plaumann Ltda.", sendo Fritz Plaumann responsável pelos serviços científicos e de escritório e, sua filha, dos assuntos administrativos. No entanto, as atividades não puderam ser iniciadas porque faltava o registro perante o IBDF, uma vez que havia a necessidade de regulamentação da criação de animais nativos em cativeiro. Entretanto, devido às inúmeras exigências para o estabelecimento da empresa de criadores de insetos, como por exemplo, o capital mínimo exigido de um milhão de cruzeiros, levou Plaumann a cancelar a abertura de firma "Entomologia Plaumann Ltda.",23

Ainda no ano de 1978 foram concedidas licenças para Plaumann reaproveitar a madeira verde ou semi-verde, proveniente de desmatamento, com a finalidade de criar insetos, principalmente as brocas e os carunchos, como apresentado no seguinte trecho da carta do IBDF de Florianópolis: "Em atenção ao expediente de Vossa senhoria, datado de 25 de abril último, vimos pela presente, autorizar a utilização de madeira proveniente de desmatamento, para a criação de insetos destinados ao estudo científico". ${ }^{24}$

Cambridge: Cambridge University Press, 1997 (1996).

22 SPESSATTO, Mary, Bortolanza. (org). O diário de Fritz Plaumann. Chapecó: Argos, p.176, 2001.

${ }^{23}$ SPESSATTO, Mary, Bortolanza. (org). O diário de Fritz Plaumann. Chapecó: Argos, 168$170,2001$.

${ }^{24}$ Trecho de correspondência do IBDF, Florianópolis, 5 de junho de 1978 para Fritz Plaumann. Fonte: Diário de Fritz Plaumann, p.171. 
Em 26 de julho de 1978, Plaumann conseguiu autorização até o final daquele ano para coletar material entomológico para fins científicos "isentando-se da mesma forma da guia de trânsito, quando o material se destinar a instituições cientificas oficiais". ${ }^{25}$

Porém, ao solicitar nova autorização para coleta ao IBDF, Plaumann recebeu resposta sinalizando a necessidade dele se filiar a uma instituição científica:

Prezado Sr. Plaumann,

Pelo presente queremos expressar nossa admiração pelo trabalho entomológico que o senhor vem realizando e ainda nos escusar pela demora em receber sua solicitação. Para não entrarmos em detalhes, gostaria de esclarecer que a Lei de Proteção à Fauna admite a coleta de material para cientistas pertencentes ou indicados por instituições científicas nacionais, as quais se responsabilizam pelo pesquisador. Neste caso, qualquer exportação de material deveria ser feita com a aprovação daquela instituição. Recebemos ótimas referências do Museu de Zoologia da USP e do Dr. Moure, mas nenhuma indicação. Seria oportuno que o senhor se filiasse a uma instituição científica, o que cremos, não será difícil. Por outro lado informamos que o comércio de espécies silvestres é proibido pela Lei de Proteção à Fauna, não podendo se caracterizar em nenhuma transação com animais silvestres para qualquer finalidade. No momento, expediremos uma licença de coleta provisória, esperando resolver definitivamente o problema em um futuro próximo. Sendo o que apresenta no momento, reiteramos protestos de consideração. ${ }^{26}$

Essa licença provisória dada a Plaumann em 6 de junho de 1980 e válida até 31 de dezembro de 1980 autorizava-o a coletar e transportar insetos dentro do território nacional apenas com finalidade científica. Dois pontos importantes chamam a atenção nas negociações de Plaumann com o IBDF. Primeiramente, perante a legislação brasileira Plaumann era um

25 Trecho de correspondência do IBDF, Florianópolis, 25 de julho de 1978 para Fritz Plaumann. Fonte: Diário de Fritz Plaumann, p.171.

${ }^{26}$ SPESSATTO, Mary, Bortolanza. (org). O diário de Fritz Plaumann. Chapecó: Argos, p.203, 2001. 
amador, principalmente no sentido do coletor não estar vinculado a nenhuma instituição científica. E, em segundo lugar, mesmo sendo considerado um amador, Plaumann conseguiu licença especial para a coleta temporária devido ao fato de seu nome e seu trabalho serem amplamente conhecidos no meio científico; seu reconhecimento como um "expert" havia chegado ao conhecimento dos servidores do IBDF, como expressado na carta que recebeu desse órgão em 1980, transcrita acima. ${ }^{27}$

Nas solicitações de licença para coleta e transporte enviadas ao IBDF sempre havia a menção de algumas questões que aqui devemos destacar, a começar com a importância de seu trabalho em prol da fauna brasileira, uma vez que salienta em vários momentos o tempo de vida curto que os insetos têm ao afirmar "se não for coletado hoje, morre nos próximos dias ou semanas, de velhice, sem deixar rastros". 28

Ademais, Plaumann constantemente criticava a utilização de agrotóxicos "e assim vai a destruição da fauna, em conjunto como envenenamento pelos herbicidas e inseticidas" ${ }^{29}$ referindo-se que seu espaço de coleta era nos restinhos de mata virgens ainda existentes, sempre destacando que suas pesquisas pudessem servir de base para futuros estudos. Por fim, em inúmeras ocasiões, citou o nome dos especialistas famosos no mundo científico com os quais manteve contato durante vários anos, como August Reichensperger, frei Thomas Borgmeier, Ângelo Moreira da Costa Lima, Pe. W.W Kempf, Erwin Lindner, dentre outros, como uma forma de dar importância a seu trabalho como coletor e colecionador, ressaltando que possuía retratos com dedicatórias dos cientistas citados.

Portanto, podemos analisar essas referências como uma estratégia para conseguir a licença temporária de coleta. Além disso, Plaumann estava sempre muito atento às intervenções no meio ambiente que estavam acontecendo na região, afetando a flora e fauna e citando esses acontecimentos em seus pedidos:

27 SPESSATTO, Mary, Bortolanza. (org). O diário de Fritz Plaumann. Chapecó: Argos, 2001.

28 SPESSATTO, Mary, Bortolanza. (org). O diário de Fritz Plaumann. Chapecó: Argos, p. 213, 2001.

${ }^{29}$ SPESSATTO, Mary, Bortolanza. (org). O diário de Fritz Plaumann. Chapecó: Argos, p. $197,2001$. 
Também no ano que vem pretendo continuar com as pesquisas sobre o ecossistema do Alto Uruguai, o qual é um dos mais importantes, tendo em vista que incluo vastas zonas inundáveis, conforme o plano de eletrificação a se realizar no conjunto de represas ao longo do Rio Uruguai o qual, consequentemente, eliminará parte da Fauna Entomológica, Zoológica e Flora, também desse ecossistema, principalmente as espécies endêmicas. Trata-se principalmente da área Norte do Rio Uruguai e suas afluentes, tais como os rios Jacutinha, Uvá, Ariranhazinha, Ariranha, Irani e outros. E é por isso que venho pedir, respeitosamente, que se digne de conceder uma Licença especial para Coleta de Insetos, com finalidade científica. Suponho que não exista outra pessoa que pudesse assumir o compromisso de executar tal empreendimento, pelo menos não no espaço do curto tempo que nos resta para tal finalidade. $\mathrm{O}$ plano de trabalho abrange, principalmente, os seguintes grupos, sendo:

1) Coleópteros: Dryopidae, Elmidae, Psephenidae;

2) Diptera-Nematocera: Tipulidae, Blepharoceridae, Culidae, Psychodidae, Scatopsidae, Sciaridae, Bibionidae, Macroceridae, Phyneidae, Mecetophinidae, Ceroplatidae, Ceropogonidae, Simulidae, Chironimidae e outros;

3) Plecoptera;

4) Trichoptera;

5) Ephemeridae.

Naturalmente, em um ano não pode ser concluído tudo. Esperando favorável deferimento, desde já muito grato, subscrevo-me, atenciosamente. ${ }^{30}$

A região onde se encontravam os rios citados por Plaumann realmente foi atingida pela construção de usinas hidrelétricas. ${ }^{31}$ Plaumann

\footnotetext{
30 SPESSATTO, Mary, Bortolanza. (org). O diário de Fritz Plaumann. Chapecó: Argos, p.217-218, 2001.

${ }^{31}$ Nesse momento devemos destacar a construção da Usina Hidrelétrica de Itá, localizada no rio Uruguai entre os municípios de Itá (SC) e Aratiba (RS). As primeiras discussões sobre sua construção remetem ao início da década de 1980, período que Plaumann encaminha o pedido ao IBDF, quando se iniciam os estudos sobre a exploração energética do rio Uruguai realizado pela Eletrosul. A Usina iniciou suas atividades em 1996, atingindo no total de 11 municípios,
} 
viu seu campo de pesquisas, os rios e seus entornos, ameaçados por esses empreendimentos. Para ele, era essencial que não houvesse interrupções em suas coletas "para encontrar algumas espécies desconhecidas da ciência, antes que sejam eliminadas". 32

Na luta para conseguir as licenças temporárias para coletar material entomológico, Plaumann passou de 25 de julho de 1979 até 6 de junho de 1980 encaminhando correspondências para o IBDF. Primeiramente, comunicando-se com o escritório de Florianópolis e, posteriormente, os seus pedidos foram encaminhados para Brasília e seu contato estabeleceuse com a capital federal. No entanto, a licença para coleta temporária só foi deferida em 6 de junho de 1980 e, nos anos seguintes, entre 1981 e 1983, sempre com validade de um ano. A solução encontrada para a continuação de seu trabalho como coletor, seguindo a legislação brasileira, só ocorreu no ano de 1983 através do vínculo com a FAPES (Fundação Alto Uruguai para a pesquisa e o Ensino Superior) através de demanda da Fundação para que Plaumann formasse uma coleção entomológica para a instituição. Plaumann, agora, seria pesquisador da Fundação, indo de encontro ao artigo 14 da Lei $\mathrm{n}^{\circ}$ 5197/67, que estabelecia que licenças especiais só poderiam ser concedidas aos cientistas pertencentes às instituições científicas. Em seu diário, Plaumann relatou:

[...] entrou em contato comigo o presidente da Fundação Alto Uruguai para a pesquisa e o Ensino Superior (FAPES), de Erechim, para obter a minha ajuda na formação da coleção entomológica, que aceitava sob a condição de arrumar licença Especial do IBDF em Brasília para tal finalidade, o que foi feito com êxito. [...] Ontem recebi o ofício e a Licença Especial de Coleta como pesquisador da FAPES, garantindo desta forma a continuidade das pesquisas sobre a entofauna regional do Alto Uruguai. ${ }^{33}$

sendo 7 da região do Alto Uruguai Catarinense. Além da UHE de Itá, muitas PCHs (Pequenas Centrais Hidrelétricas), como por exemplo, em Arvoredo (SC), município localizado no rio Irani nos últimos anos. Em outras palavras, muitas das regiões de coletas de Plaumann foram atingidas pela construção de centrais Hidrelétricas Disponível em: http://pm.fecam.org.br/conteudo/?item $=21115 \& \mathrm{fa}=4850$. Acessado em: 06 de maio de 2015.

32 SPESSATTO, Mary, Bortolanza. (org). O diário de Fritz Plaumann. Chapecó: Argos, p. $214,2001$.

33 SPESSATTO, Mary, Bortolanza. (org). O diário de Fritz Plaumann. Chapecó: Argos, 2001. 
Em relação aos contatos estabelecidos com universidades e especialistas do exterior, Plaumann encerrou essa comunicação devido às inúmeras exigências impostas pelo governo brasileiro:

Para receber autorização de fazer remessas para o exterior, é exigido que o interessado do exterior solicite seu credenciamento junto ao IBDF, bem como evitar uma relação dos insetos, quantidade por indivíduos e por espécies e o fim a que se destinam. O problema é que o interessado, principalmente especialista, necessita de material não identificado para os seus estudos, querendo identificá-las, descrever as espécies que habitam a região onde eu coleto. Outrossim, eu não posso informá-las, visto que tenho que enviá-las primeiro a um especialista que estuda, descreve e publica as espécies novas, devolvendo-me parte do material e uma cópia da sua publicação. E sem, poder seguir esse processo, tudo tem que ficar na estaca "zero". O contato com os especialistas e universidades no exterior terminou. ${ }^{34}$

\section{Conclusão}

Com base no breve panorama discorrido, observamos que a legislação brasileira sofreu profundas influências a partir de discussões internacionais latentes na década de 1970, como a Conferência de Estocolmo e a CITES. Mesmo o Brasil já tendo uma legislação vigente, Lei de proteção à fauna de 1967, que visava a regulamentação da coleta de espécimes, Fritz Plaumann continuava suas atividades de coletor de maneira rotineira e só foi sentir sua interferência em 1975, depois da implantação da CITES no Brasil, ocorrida naquele mesmo ano. As novas exigências para comercialização de espécimes e a dificuldade enfrentada em regulamentar sua situação como coletor junto ao IBDF levaram Plaumann a reduzir o ritmo de suas coletas científicas por alguns períodos.

Até a década de 1980 a coleção formada por Plaumann ficava abrigada na residência da família, mas, depois de todas as restrições que

\footnotetext{
${ }^{34}$ SPESSATTO, Mary, Bortolanza. (org). O diário de Fritz Plaumann. Chapecó: Argos, p.210, 2001.
} 
haviam sido impostas com a nova legislação, ele decidiu vender sua coleção para Prefeitura Municipal de Seara (SC), ideia essa que já vinha sendo elaborada por ele, como observado em carta escrita no ano de 1964 para Carlos Alberto Seabra. Nela, Plaumann já dá indícios de que pretendia vender, futuramente, a sua coleção, no caso, a coleção de cerambicídeos:

Quanto a minha colleção de cerambycídeos, a única coisa que no momento posso vos prometter, e que dará "preferencia" a V.S no caso de querer vende-la. No momento não pretendo vender essa coleção a qual de um certo modo, "faz parte da minha vida". Naturalmente vou vender-a mais tarde quando ficar "velho"... si não morro antes. Por enquanto estou ainda trabalhando para a dita coleção e creio que me será possível de continuar ainda por algum tempo apesar de já ter 62 anos. E, se, por acaso o fim da chegar mais rápido que pensamos a minha esposa esta a por dessa promessa e pode avisar V.S. ${ }^{35}$

Mesmo após a venda da coleção, Plaumann continuou a incrementar a coleção que hoje é abrigada pelo Museu Entomológico Fritz Plaumann, do qual Plaumann foi o primeiro diretor. A autorização para realizar as coletas após sua inserção na FAPES (Fundação Alto Uruguai para a pesquisa e o Ensino Superior) contribuiu para que mantivesse suas atividades de coleta.

Através das atividades de Plaumann foi possível analisar o quanto o ato de coletar e comercializar espécimes da fauna brasileira por colecionadores e coletores amadores foi afetado pela nova legislação, pois sem haver um vínculo com uma instituição científica não era permitido que se realizasse coletas. Para os autodidatas como Plaumann, a solução foi a filiação em uma instituição científica ou o encerramento das atividades.

A trajetória científica de Fritz Plaumann também nos permite compreender o contexto envolto no trabalho de cientistas amadores. A rede formada entre diferentes grupos de profissionais, amadores, e comerciantes interessados em colecionar e conhecer os habitantes das florestas sulamericanas. A troca realizada entre os diferentes grupos dessa rede contribuiu

\footnotetext{
35 Trecho extraído de carta de Fritz Plaumann para Carlos Alberto Seabra. Nova Teutônia, 14 de agosto de 1964.
} 
para a circulação e produção de conhecimento, mas também acabou afetada pelas mudanças que regulamentou a comercialização de espécimes da fauna e flora. 